Original article

\title{
Evaluation of the relationship between identity styles and leisure time activities in adolescents
}

\author{
Zahra Unesi ${ }^{1}$, Samaneh Nakhaee ${ }^{1 *}$, Thayebeh Khazaie ${ }^{1}$, Zahra Amouzeshi ${ }^{1}$, Sima Kaheni ${ }^{2}$
}

(Received: 20 Aug 2015; Accept: 11 Nov 2015)

\begin{abstract}
Background and Purpose: Personal identity is the sense of being distinct from other individuals, which is of paramount importance during adolescence. Modern theories suggest that young adults perceive personal identity in different ways, and several factors affect this phenomenon. Leisure time activities are a significant element during adolescence. This study aimed to evaluate the relationship between identity styles and leisure activities in adolescents.

Methods: This descriptive-correlational study was conducted on 370 high school students in Birjand, Iran in 2013.Students were selected via stratified two-stage random sampling. Data were collected using Identity Style Inventory (ISI-6G, Berzonsky) including domains of informational, normative, diffuse-avoidant and commitment identity styles, and leisure time questionnaire including indices of different products, activities, spaces and internet use, in leisure time. Data analysis was performed using student's T-test, MannWhitney, one-way ANOVA, Kruskal-Wallisand Spearman's correlation-coefficient, and P value of less than 0.05 was considered significant.

Results: In this study, a significant positive correlation was found between diffuse-avoidant/informational identity styles and use of internet $(\mathrm{P}<0.05)$, informational style and use of space $(\mathrm{P}=0.01)$, normative style and leisure activities $(\mathrm{P}=0.02)$ and commitment style with different products $(\mathrm{P}=0.03)$. Moreover, a significant negative correlation was observed between commitment identity style and use of internet $(\mathrm{P}=0.02)$.

Conclusion: According to the results of this study, leisure time activities have a remarkable effect on identity styles of adolescents. Therefore, families and organizations concerned with adolescence affairs should monitor quality of leisure activities in teenagers.
\end{abstract}

Keywords: Adolescent, Identity styles, Leisure time

\section{Introduction}

As an inevitable stage of human evolution and a period of growth and sweeping changes, adolescence refers to the age range of 10-19 years (1). Adolescence is characterized by identification and modification of personal identity $(2,3)$. In this period, young adults are concerned about authentication with their turbulent role, which might appear as a psychosocial phenomenon $(2,4,5)$.

Sense of personal identity or mental selfimage is formed based on values, desirable traits, accomplishments and approvals that adolescents visually perceive in interaction with parents, educators, friends and acquaintances (6). Personal identity is considered as a major psychological issue drawing the attention of many researchers in recent years (4). This fundamental concept helps an individual to connect with past experiences in order to achieve sustainability and integration in life (6).

To explore information about personal identity, Berzonsky classified this concept into three

\footnotetext{
1,* Corresponding author: Faculty of Nursing and Midwifery, Birjand University of Medical Sciences, Birjand, Iran. Email: nakhaee38@yahoo.com ${ }^{2}$ Department of Pediatric Nursing, Faculty Member at Nasibeh Nursing and Midwifery School, Mazandaran University of Medical Sciences, Mazandaran, Iran
} 
categories of informational, normative and diffuse-avoidant styles. People with informational identity style actively search, evaluate and process information about themselves. Normally, these individuals are uncertain about structures of their personality and would like these structures to be tested in various occasions. Depending on received feedback, these individuals might feel urged to reconsider certain aspects of their identity.

In normative identity style, decision-making of the individual is largely influenced by expectations or demands of other people. Research depicts these individuals as alert and cheerful; however, they show little tolerance for uncertainty and are in desperate need for cognitive structure. People with diffuse-avoidant identity style are frequently unwilling to confront personal issues and decisions. In long-term interaction with other people, these individuals may be controlled by situational demands and incentives (7).

In modern communities, numerous sources are used to investigate identity styles, which emphasizes the constantly changing nature of this phenomenon. As such, researchers have been concerned with the issue of personal identity and its associated challenges (8).

According to the literature, authentication of personal identity in adolescents is affected by several factors, such as family and school environments, occupation status, peer models of leisure activities and mass media $(5,9,10)$. Recent findings suggest that providing adolescents with opportunities to discover their personal and social abilities plays a pivotal role in the proper formation of personal identity $(3,9)$.

According to the definition proposed by the International Sociology Association (ISA), leisure time consists of a set of activities chosen by an individual for relaxation, recreation, knowledge development, non-profit acquisition and voluntarily social activities after relief from daily life engagements (11).

Since teenagers spend almost half their time for leisure activities, special attention is needed to optimize the quality of this time $(3,5)$. As such, researchers have been focused on the quality of leisure activities as a way of developing life skills in young adults. Leisure activities during adolescence not only affect free time hobbies during adulthood (12), but they also lay the ground for discovering personal interests, as well as the strengths and weaknesses of an individual (3).

High-quality leisure activities guarantee healthier social behaviors, improved academic performance, psychological well-being and character nourishment. Furthermore, leisure activities could largely contribute to stress management, which is an integral part of adolescence period (12). On the other hand, negligence of leisure activities and lack of proper management in this regard could lead to introversion, isolation, passivity and lack of creativity (13).

Pediatric and community health nurses, school health experts and family physicians could offer beneficial advice for proper decision-making about leisure activities of teenagers, which will ultimately enhance sense of personal identity in young adults (14).

Several studies have evaluated the relationship between leisure time quality and identity styles among teenagers reporting a significant correlation between leisure activities and identity development, character formation and self-image. For instance, it was stated in a research that people authenticate their identity through activities such as leisure activities (15).

Moreover, results of a qualitative study suggested that leisure activities could evoke experiences associated with the perceived personal identity of people (10).

Findings of another study also confirmed there markable effect of adolescent leisure activities on self-image of adults (16). However, results of another study were indicative of no significant correlation between total score of leisure activity and personal identity (9). Domestic studies in this area are limited and mostly focused on the role of other variables, such as social identity, national identity, crime rate and health-related quality of life, on leisure activities $(12,17,18)$.

Considering the importance of personal identity and leisure activities, and given the limited and 
conflicting results of other studies performed on young adult population of Iran in this area, this study aimed to evaluate the correlation between quality of leisure activities and identity styles in adolescents.

\section{Materials and methods}

This descriptive-correlational study was conducted on a study population consisting of all high school students in Birjand, Iran $(n=9,870)$ during the academic year of 2013. In total, 370 students were selected via stratified two-stage random sampling. For sampling, study location (Birjand) was divided into four districts, and list of schools in each district was prepared. Also, we randomly selected one male-only and one femaleonly high school from each area. In each school, one class was selected randomly at each grade, and 16 students were randomly chosen from each class.

Sample size of the study was determined at 370 participants using Cochran's formula with error rate of 0.01 , estimation accuracy of $\mathrm{d}=0.05$ and maximum variance of $\mathrm{pq}=0.25$.

Data were collected using demographic questionnaire (age, sex, high school level, place of residence, and parental education status and occupation), Identity Style Inventory (ISI-6G) and leisure time questionnaire. Questionnaires were completed and collected under supervision of a trained research assistant with prior experience in the field of adolescent health. Before data collection, objectives of the study were explained to participants, and terms of confidentiality were assured in accordance with the instructions of research department.

ISI-6 Gwas first created by Berzonsky and revised shortly after. This questionnaire consists of 40 questions, out of which 30 items evaluate identity styles, as follows: informational identity style (11 items), normative identity style ( 9 items) and diffuseavoidant identity style (10 items). In addition, 10 items are designed to assess commitment identity style. All items are scored based on the following range: strongly disagree, partly disagree, not sure, partly agree and strongly agree, and scales are graded between 0-5 (19).
Due to different number of items in each domain of ISI-G6, corresponding scores were determined for each domain (range:0-100). Higher scores in each area of ISI-G6 represented the dominance of each identity style, and questions 9, 11, 14 and 20 were scored in a reversed manner. In the research by Hejazi, Cronbach's alpha coefficient for informational, normative and diffuse-avoidant styles was calculated at $0.77,0.60$ and 0.66 , respectively, and it was 0.68 for commitment style (20).

In this study, leisure time questionnaire was compiled based on the version proposed by Khaje Noory, which was designed based on previous findings of Agnew and Peterson and Yin et al. $(12,21,22)$. This questionnaire has four indices, including activities, use of space, different products and use of internet in leisure time, and duration of each index is evaluated separately.

Space usage in leisure time accounted for four items (e.g., religious congregations, arts, training courses and outdoor activities), and leisure activities accounted for three items (e.g., meeting friends, regular exercise and visiting beauty salons). Moreover, index of different products consisted of eight items (using cell phones, watching TV, leisurely or academic reading, listening to music, reading newspapers or magazines).

Finally, five items evaluated use of internet in leisure time (e.g., chatting, sexual content, educational programs, watching movies, playing computer games). In this questionnaire, respondents specified the average time they would spend on each domain.

Validity of leisure time questionnaire was determined using content validity, relevant articles and expert opinion of eight faculty members at Nursing and Midwifery Faculty of Birjand University of Medical Sciences. In addition, reliability of this questionnaire was confirmed by calculating Cronbach's alpha coefficient $(\alpha=0.88)$.

Data analysis was performed using descriptive statistics (mean and standard deviation) and analytical tests in SPSS V.18. Normal distribution of data was determined using KolmogorovSmirnov test. Afterwards, indices of leisure time and informational, normative and diffuse- 
avoidant identity styles were compared based on demographic variables using Kruskal-Wallis and Mann Whitney U tests. Moreover, mean scores of diffuse-avoidant style in terms of demographic variables were compared using independent T-test and one-way analysis of variance (ANOVA). To investigate the relationship between leisure time indices and identity styles, we used Spearman's correlation-coefficient and multivariate linear regression, and $\mathrm{P}$ value of less than 0.05 was considered significant.

\section{Results}

In this study, mean age of participants $(n=370)$ was $16.29 \pm 3.65$ years, and the majority of students were male $(\mathrm{n}=228,61.96 \%)$ and first child of family $(n=120,31.3 \%)$. Fathers $(n=182,50.42 \%)$ and mothers $(n=239,66.20 \%)$ of more than half of students had secondary or lower education levels, and fathers were mostly self-employed (33.70\%), while mothers were mostly housewives (83.38\%).

According to our observations, the most predominant identity styles were informational style (39.09 \pm 6$)$, commitment style $(34.82 \pm 5.25)$, normative style $(33.51 \pm 4.54)$ and diffuse-avoidant style (28.15 \pm 5.75$)$, respectively. Among different indices of leisure time, domains of space usage and outdoor activities $(2.69 \pm 4.21)$ occupied most of free time for students.

In domain of activities, spending time with friends had the longest duration $(4.03 \pm 7.92)$, while in domain of different products, reading $(8.67 \pm 12.27)$ and watching TV (5.7 7.96$)$ had the longest durations. Finally, watching movies accounted for the longest duration in the area of internet use (2.48 \pm 4.07$)$.

Results of this study were indicative of a

Table 1. Comparison of mean scores of identity styles in terms of demographic variables in high school students

\begin{tabular}{|c|c|c|c|c|c|c|c|c|c|}
\hline \multirow{2}{*}{\multicolumn{2}{|c|}{ Demographic Characteristics }} & \multicolumn{2}{|c|}{ Informational Style } & \multicolumn{2}{|c|}{ Normative Style } & \multicolumn{2}{|c|}{ Diffuse-Avoidant Style } & \multicolumn{2}{|c|}{ Commitment Style } \\
\hline & & Mean \pm SD & Test Results & Mean \pm SD & Test Results & Mean \pm SD & Test Results & Mean \pm SD & Test Results \\
\hline \multirow{4}{*}{$\begin{array}{l}\text { Age } \\
\text { (year) }\end{array}$} & $14-15.5$ & $38.49 \pm 6.73$ & \multirow{4}{*}{$\begin{array}{l}\mathrm{P}=0.37 \\
\chi^{2}=3.13\end{array}$} & $33.78 \pm 4.64$ & \multirow{4}{*}{$\begin{array}{l}\mathrm{P}=0.23 \\
\chi^{2}=4.3\end{array}$} & $28.01 \pm 5.4$ & \multirow{4}{*}{$\begin{array}{l}P=0.93 \\
f=0.54\end{array}$} & $35.06 \pm 5.86$ & \multirow{4}{*}{$\begin{array}{c}\mathrm{P}=0.6 \\
\chi^{2}=1.83\end{array}$} \\
\hline & $16-16.5$ & $38.63 \pm 5.3$ & & $33.21 \pm 4.56$ & & $28 \pm 5.98$ & & $35.2 \pm 4.76$ & \\
\hline & $17-17.5$ & $39.62 \pm 5.2$ & & $34.14 \pm 4.26$ & & $28.44 \pm 5.86$ & & $34.89 \pm 5.24$ & \\
\hline & $>18$ & $39.76 \pm 5.2$ & & $32.76 \pm 4.22$ & & $28.37 \pm 5.46$ & & $33.96 \pm 3.99$ & \\
\hline \multirow{2}{*}{ Gender } & Male & $39.53 \pm 5.94$ & \multirow{2}{*}{$\begin{array}{l}P=0.06 \\
z=-1.82\end{array}$} & $33.31 \pm 4.53$ & \multirow{2}{*}{$\begin{array}{l}P=0.37 \\
\mathrm{Z}=-0.89\end{array}$} & $28.69 \pm 5.96$ & \multirow{2}{*}{$\begin{array}{l}P=0.02 \\
t=-2.26\end{array}$} & $34.24 \pm 5.05$ & \multirow{2}{*}{$\begin{array}{l}P=0.006 \\
z=-2.75\end{array}$} \\
\hline & Female & $38.32 \pm 6.07$ & & $33.76 \pm 4.49$ & & $27.29 \pm 5.27$ & & $35.75 \pm 5.16$ & \\
\hline \multirow{4}{*}{$\begin{array}{l}\text { Level of } \\
\text { Education }\end{array}$} & First Grade of High School & $38.78 \pm 6.34$ & \multirow{4}{*}{$\begin{array}{c}\mathrm{P}=0.7 \\
\chi^{2}=1.41\end{array}$} & $33.57 \pm 4.82$ & \multirow{4}{*}{$\begin{array}{l}\mathrm{P}=0.33 \\
\chi^{2}=3.4\end{array}$} & $28.7 \pm 5.69$ & \multirow{4}{*}{$\begin{aligned} P & =0.61 \\
\mathrm{f} & =0.6\end{aligned}$} & $35.09 \pm 5.39$ & \multirow{4}{*}{$\begin{array}{l}\mathrm{P}=0.83 \\
\chi^{2}=0.84\end{array}$} \\
\hline & Second Grade of High School & $38.53 \pm 6.01$ & & $34.04 \pm 4.29$ & & $27.48 \pm 5.47$ & & $35.25 \pm 5.7$ & \\
\hline & Third Grade of High School & $39.48 \pm 6.08$ & & $32.9 \pm 4.71$ & & $28.22 \pm 5.96$ & & $34.73 \pm 4.73$ & \\
\hline & Pre-university & $39.57 \pm 5.53$ & & $33.88 \pm 4.15$ & & $27.96 \pm 5.73$ & & $34.59 \pm 4.93$ & \\
\hline \multirow{4}{*}{ Birth Order } & First Child & $38.51 \pm 6.16$ & \multirow{4}{*}{$\begin{array}{l}\mathrm{P}=0.27 \\
\chi^{2}=3.89\end{array}$} & $33.19 \pm 4.61$ & \multirow{4}{*}{$\begin{array}{l}\mathrm{P}=0.53 \\
\chi^{2}=2.2\end{array}$} & $27.84 \pm 5.72$ & \multirow{4}{*}{$\begin{array}{l}\mathrm{P}=0.26 \\
\mathrm{f}=1.32\end{array}$} & $34.99 \pm 5.74$ & \multirow{4}{*}{$\begin{array}{l}\mathrm{P}=0.64 \\
\chi^{2}=1.68\end{array}$} \\
\hline & Second Child & $38.5 \pm 5.8$ & & $33.68 \pm 4.63$ & & $29.25 \pm 5.69$ & & $34.44 \pm 4.58$ & \\
\hline & Third Child & $40.44 \pm 5.08$ & & $34.09 \pm 4.25$ & & $27.41 \pm 5.81$ & & $35.4 \pm 4.98$ & \\
\hline & and Above Fourth Child & $39.41 \pm 6.29$ & & $33.45 \pm 4.55$ & & $28.08 \pm 5.77$ & & $34.65 \pm 5.28$ & \\
\hline \multirow{3}{*}{$\begin{array}{l}\text { Education Level } \\
\text { of Father }\end{array}$} & Below Diploma & $39.53 \pm 5.92$ & \multirow{3}{*}{$\begin{array}{l}P=0.26 \\
\chi^{2}=2.63\end{array}$} & $34.02 \pm 4.46$ & \multirow{3}{*}{$\begin{array}{l}\mathrm{P}=0.14 \\
\chi^{2}=3.81\end{array}$} & $28.35 \pm 5.67$ & \multirow{3}{*}{$\begin{array}{l}P=0.68 \\
f=0.38\end{array}$} & $35.08 \pm 4.85$ & \multirow{3}{*}{$\begin{array}{c}\mathrm{P}=67 \\
\chi^{2}=0.79\end{array}$} \\
\hline & Diploma & $38.27 \pm 6.44$ & & $32.91 \pm 4.93$ & & $28.39 \pm 5.42$ & & $34.69 \pm 5.25$ & \\
\hline & Higher and B.A & $39.46 \pm 5.45$ & & $33.23 \pm 3.85$ & & $27.69 \pm 6.31$ & & $34.68 \pm 5.84$ & \\
\hline \multirow{3}{*}{$\begin{array}{l}\text { Education Level } \\
\text { of Mother }\end{array}$} & Below Diploma & $39.39 \pm 6.1$ & & $33.85 \pm 4.49$ & & $28.01 \pm 5.58$ & & $35.02 \pm 4.99$ & \\
\hline & Diploma & $38.6 \pm 6.09$ & $\begin{array}{l}\mathrm{P}=0.47 \\
\chi^{2}=1.49\end{array}$ & $32.97 \pm 4.74$ & $\begin{array}{l}\mathrm{P}=0.21 \\
\chi^{2}=3.05\end{array}$ & $28.8 \pm 5.79$ & $\begin{array}{l}P=0.2 \\
f=1.57\end{array}$ & $35.05 \pm 5.28$ & $\begin{array}{l}\mathrm{P}=0.44 \\
\chi^{2}=1.6\end{array}$ \\
\hline & Higher and B.A & $38.62 \pm 5.49$ & & $33.09 \pm 4.35$ & & $28.39 \pm 6.63$ & & $33.97 \pm 5.85$ & \\
\hline Occupation of & Self-employed & $38.62 \pm 6.59$ & $\mathrm{P}=0.23$ & $33.41 \pm 4.81$ & $\mathrm{P}=0.7$ & $28.48 \pm 5.71$ & $\mathrm{P}=0.33$ & $34.71 \pm 5.02$ & $\mathrm{P}=0.54$ \\
\hline Father & Employee & $39.67 \pm 5.15$ & $z=-1.18$ & $33.69 \pm 4.15$ & $\mathrm{z}=-0.27$ & $27.88 \pm 5.8$ & $\mathrm{t}=-0.95$ & $35.03 \pm 5.33$ & $\mathrm{z}=-0.6$ \\
\hline Occupation of & Employee & $38.08 \pm 6.35$ & $\mathrm{P}=0.22$ & $32.7 \pm 4.47$ & $\mathrm{P}=0.15$ & $28.55 \pm 6.5$ & $\mathrm{P}=0.59$ & $34.32 \pm 5.87$ & $\mathrm{P}=0.41$ \\
\hline Mother & Housewife & $39.24 \pm 5.97$ & $\mathrm{z}=-1.22$ & $33.67 \pm 4.53$ & & $28.11 \pm 5.57$ & $\mathrm{t}=0.52$ & $34.91 \pm 5.03$ & $\mathrm{z}=-0.82$ \\
\hline
\end{tabular}


Table 2. Comparison of mean scores of leisure time indices in terms of demographic variables in high school students

\begin{tabular}{|c|c|c|c|c|c|c|c|c|c|}
\hline \multirow{2}{*}{\multicolumn{2}{|c|}{ Demographic Characteristics }} & \multicolumn{2}{|c|}{ Space Usage } & \multicolumn{2}{|c|}{ Activities } & \multicolumn{2}{|c|}{ Different Products } & \multicolumn{2}{|c|}{ Internet Use } \\
\hline & & Mean \pm SD & Test Results & Mean \pm SD & Test Results & Mean \pm SD & Test Results & Mean \pm SD & Test Results \\
\hline \multirow{4}{*}{ Age (year) } & $14-15.5$ & $7.36 \pm 8.08$ & \multirow{4}{*}{$\begin{array}{l}\mathrm{P}=0.14 \\
\chi^{2}=5.38\end{array}$} & $6.17 \pm 8.13$ & \multirow{4}{*}{$\begin{array}{c}\mathrm{P}=0.002 \\
\chi^{2}=14.46\end{array}$} & $23.97 \pm 19.78$ & \multirow{4}{*}{$\begin{array}{c}\mathrm{P}=0.00 \\
\chi^{2}=25.87\end{array}$} & $6.31 \pm 8.9$ & \multirow{4}{*}{$\begin{array}{c}\mathrm{P}=0.00 \\
\chi^{2}=17.93\end{array}$} \\
\hline & $16-16.5$ & $7.14 \pm 10.6$ & & $6.74 \pm 9.53$ & & $25.34 \pm 24.11$ & & $6.28 \pm 13.98$ & \\
\hline & $17-17.5$ & $7.99 \pm 9.14$ & & $8.84 \pm 8.79$ & & $33 \pm 24.92$ & & $8.88 \pm 9.92$ & \\
\hline & $>18$ & $11.36 \pm 11.05$ & & $18.28 \pm 11.61$ & & $53.43 \pm 42.24$ & & $27.38 \pm 14.83$ & \\
\hline \multirow{2}{*}{ Gender } & Male & $9.11 \pm 9.63$ & \multirow{2}{*}{$\begin{array}{l}\mathrm{P}=0.00 \\
\mathrm{z}=-3.82\end{array}$} & $9.24 \pm 11.71$ & \multirow{2}{*}{$\begin{array}{l}\mathrm{P}=0.00 \\
\mathrm{z}=-5.55\end{array}$} & $30.31 \pm 34.46$ & \multirow{2}{*}{$\begin{array}{c}\mathrm{P}=0.04 \\
\mathrm{z}=-2\end{array}$} & $11.04 \pm 16.15$ & \multirow{2}{*}{$\begin{array}{l}P=0.00 \\
z=-7.98\end{array}$} \\
\hline & Female & $6.19 \pm 9.3$ & & $5.36 \pm 8.05$ & & $28.05 \pm 23.92$ & & $3.96 \pm 11.03$ & \\
\hline \multirow{4}{*}{$\begin{array}{l}\text { Level of } \\
\text { Education }\end{array}$} & First Grade of High School & $9.45 \pm 13.98$ & \multirow{4}{*}{$\begin{array}{l}\mathrm{P}=0.03 \\
\chi^{2}=8.62\end{array}$} & $8.33 \pm 12.34$ & \multirow{4}{*}{$\begin{array}{c}\mathrm{P}=0.00 \\
\chi^{2}=19.13\end{array}$} & $28.85 \pm 34.74$ & \multirow{4}{*}{$\begin{array}{c}\mathrm{P}=0.00 \\
\chi^{2}=19.91\end{array}$} & $10.59 \pm 17.4$ & \multirow{4}{*}{$\begin{array}{c}\mathrm{P}=0.00 \\
\chi^{2}=39.89\end{array}$} \\
\hline & Second Grade of High School & $5.32 \pm 3.9$ & & $4.51 \pm 4.32$ & & $21.05 \pm 26.07$ & & $2.79 \pm 2.87$ & \\
\hline & Third Grade of High School & $7.97 \pm 7.79$ & & $9.16 \pm 13.58$ & & $28.82 \pm 34.31$ & & $9.75 \pm 15.49$ & \\
\hline & Pre-university & $9.31 \pm 10.91$ & & $8.76 \pm 8.51$ & & $36.32 \pm 32.51$ & & $10.49 \pm 17.82$ & \\
\hline
\end{tabular}

statistically significant difference between mean scores of diffuse-avoidant $(\mathrm{P}=0.02)$ and commitment identity styles $(\mathrm{P}=0.07)$. In addition, female and male students had higher mean scores in commitment and diffuse-avoidant styles, respectively. We also observed that with increasing age, rate of commitment identity style would decrease, whereas rate of informational style would increase; however, no significant difference was found between mean scores of identity styles in terms of age. Moreover, no statistically significant difference was observed between identity styles and other demographic variables such as birth order, high school level and parental employment status) (Table 1). According to our results, there was a significant difference between mean scores of internet use $(\mathrm{P}<0.001)$, different products $(\mathrm{P}<0.001)$ and leisure activities $(\mathrm{P}=0.002)$ and age of students. It is also noteworthy that index of different products had the highest mean score in all age groups, and students above 18 years had the highest mean score in domain of different products.

As for other domains of leisure time questionnaire, obtained mean scores were almost equal, and different products increased with age of students. Other results were indicative of a significant difference between male and female students in terms of leisure activities (significance level: $\% 5, \mathrm{P}<0.05$ ), while mean score of different products was comparatively higher among male students (Table 2).

On the other hand, no significant difference was observed between mean of leisure time indices and birth order, and mean of different products in all indices was lowest in teenagers born with birth order of six or above. It is noteworthy that the difference between mean scores of leisure time indices at different high school levels was significant at $\% 5(\mathrm{P}<0.05)$.

In almost all participants, mean of different products increased in all subscales with higher school level, and pre-university and second grade students had the highest and lowest duration in

Table 3. Correlations between identity styles and domains of leisure time in high school students

\begin{tabular}{|c|c|c|c|c|c|}
\hline \multicolumn{2}{|c|}{ Spearman's Correlation-coefficient } & \multirow{2}{*}{$\frac{\text { Informational Style }}{0.19}$} & \multirow{2}{*}{$\frac{\text { Normative Style }}{0.1}$} & \multirow{2}{*}{$\begin{array}{c}\text { Diffuse-Avoidant Style } \\
0.11\end{array}$} & \multirow{2}{*}{$\begin{array}{c}\text { Commitment Style } \\
0.08\end{array}$} \\
\hline Sno & Correlation-coefficient & & & & \\
\hline spacts & P-value & 0.00 & 0.06 & 0.03 & 0.12 \\
\hline \multirow{2}{*}{ Activities } & Correlation-coefficient & 0.11 & 0.12 & 0.1 & -0.05 \\
\hline & $\mathrm{P}$-value & 0.03 & 0.02 & 0.058 & 0.33 \\
\hline \multirow{2}{*}{ Different Products } & Correlation-coefficient & 0.16 & 0.12 & -0.04 & 0.09 \\
\hline & P-value & 0.002 & 0.02 & 0.46 & 0.08 \\
\hline \multirow{2}{*}{ Internet Use } & Correlation-coefficient & 0.11 & 0.07 & 0.26 & -0.11 \\
\hline & P-value & 0.03 & 0.15 & 0.00 & 0.04 \\
\hline
\end{tabular}


Table 4. Coefficients of regression analysis for relationships between adolescent identity styles and leisure time indices

\begin{tabular}{|c|c|c|c|c|c|c|c|}
\hline Dependent Variable & Independent Variable & Beta Statistics & S.E & Beta Statistics & $\mathrm{t}$ & P-value & Adjusted R-square \\
\hline Diffuse-avoidant Style & Internet Use & 0.12 & 0.03 & 0.18 & 3.37 & 0.001 & 0.032 \\
\hline \multirow{2}{*}{ Commitment Style } & Internet Use & -0.07 & 0.03 & -0.12 & -2.19 & 0.02 & \multirow{2}{*}{0.016} \\
\hline & Various Products & 0.02 & 0.01 & 0.12 & 2.1 & 0.03 & \\
\hline Normative Style & Activities & 0.08 & 0.03 & 0.12 & 2.19 & 0.02 & 0.012 \\
\hline \multirow{2}{*}{ Informational Style } & Space Usage & 0.11 & 0.04 & 0.13 & 2.37 & 0.01 & \multirow{2}{*}{0.036} \\
\hline & Internet Use & 0.07 & 0.04 & 0.1 & 1.85 & 0.06 & \\
\hline
\end{tabular}

these indices, respectively (Table 2).

Evaluation of the relationship between identity styles and leisure time indices was indicative of a significant difference between informational/ diffuse-avoidant styles and space usage domain, informational/normative styles and different products and activity domains, and informational/diffusion/ commitment styles with internet use.

On the other hand, increased duration of space usage resulted in increased rates of informational and diffuse-avoidant identity styles. In addition, increased duration of different products and activity resulted in increased rates of informational and normative identity styles, and increased duration of internet use led to increased rates of informational and diffusion styles and reduced commitment style (Table 3).

Results of multivariate linear regression indicated that among all domains of leisure activities, index of internet use could be a significant predictor for rates of informational and diffuse identity styles, as well as identity commitment. Also, variables of different products, activity and space usage could respectively predict commitment, normative and informational identity styles. In other words, scores of diffusion and informational styles increased by 0.12 and 0.07 , respectively, per every hour of internet use, while identity commitment score dropped by 0.07 . In addition, commitment style increased by 0.02 per each hour of different products, while normative style increased by 0.08 per each hour of activity, and informational style increased by 0.11 per each hour of space usage (Table 4).

According to the results of regression analysis, internet access plays a more pivotal role in prediction of diffusion identity style compared to other variables $(\mathrm{P}=0.12)$.

\section{Discussion}

Findings of the present study revealed a significant correlation between identity styles and leisure activities. Accordingly, the most predominant personal identity styles among high school students were informational, commitment, normative and diffuse-avoidant styles, respectively.

In one study on the same subject, students were oriented about informational, commitment, normative and avoidant identity styles (23), and it was observed that students inclined towards informational and normative styles had stronger commitment compared to those with avoidant identity. Additionally, students with avoidant identity style had lower tolerance and emotional autonomy compared to those with informational and normative styles. Also, avoidant identity style was associated with low self-esteem, depressive reactions, and psychotic and affective disorders, which led to lower public health $(20,23)$.

According to our findings, in domain of different products in leisure time, reading and watching TV occupied most of free time for high school students. In another study, researchers evaluated tendencies of female university students in Zanjan (Iran), and the results indicated that listening to music, watching TV and chat with friends were the most popular leisure activities among participants (24). In another research about leisure activities of students at Islamic Azad Universities, the most predominant leisure activities were reported to be watching TV, listening to music, non-academic reading, meeting friends and exercise, respectively (25).

Inconsistencies between the results of current research and aforementioned studies regarding the frequency of leisure activities could be due to 
differences in target groups or time of studies.

Results of the present study were indicative of a significant correlation between some components of identity styles and leisure indices. Correspondingly, a positive significant correlation was found between use of internet and informational/diffuse identity styles, space usage and informational style, leisure activities and normative style and different products with commitment identity style. On the other hand, commitment style and internet use had an inverse correlation.

In the literature, some studies have evaluated the relationship between leisure activities and identity styles (26-28). For instance, one study in this regard has reported conflicting results highlighting no association between overall score of leisure activities and identity styles of people (9). However, in that study, cooperative and structured leisure activities were found to have a significant correlation with identity styles, while inactive, non-competitive and unstructured activities were reported to have no association with personal identity. Furthermore, it was claimed that mere participation in leisure activities is unlikely to affect personal identity as much as other factors, such as experience of leisure, incentive or variety of leisure plan. Also, variety and quality of leisure activities were found to play a pivotal role in forming the sense of personal identity. It is also noteworthy that duration of leisure activities was not observed to affect identity styles (9).

In a sociological study of the relationship between leisure activities and personal identity among the youth of Babolsar (Iran), researchers attempted to provide an innovative analysis of leisure time and its relationship with perception of young adults about their "ego" or personal identity. According to the results, there was a significant positive correlation between type of leisure activities and personal identity, and leisure activities were reported to have a remarkable effect on the perception of participants about their ago or self (29).

In another research, viewpoint of young adults towards national identity and its components were evaluated on a social level. According to the results, young adults who used foreign media (e.g., internet and satellite) had a more defective perception of national identity compared to those who did not use foreign media (30). In this regard, one study has assessed the relationship between leisure activities and prevalence of delinquency reporting a significant negative correlation between organized activities and delinquent behavior (12).

In the current study, use of internet was observed as a significant predictor for diffuse-avoidant identity style. Since individuals with diffuse identity may lack stability in academic and occupational goals, self-control and emotional autonomy, they are considered as a high-risk population for educational issues, social incompatibility, low selfesteem, depressive and neuroticism reactions, and excessive alcoholism and drug abuse at younger ages. Therefore, parental supervision is necessary for establishment of leisure forums in order to offer mental and physical security, supportive ties and skill development to adolescents.

According to our findings, use of internet could lead to reduced commitment style. In a study by Alavi et al., it was claimed that excessive use of internet could endanger mental health and bring about deficiencies in certain aspects of personal identity (31). Furthermore, another research indicated that use of informational and communicative technologies could have an adverse effect on sense of national identity (32). Results of the current study suggested that despite many advantages, excessive use of internet could cause ontological changes in individuals and ultimately lead to reduced rate of commitment style and increased rate of informational/diffusion styles.

Evidence suggests that people with curiosity may show high or low levels of commitment. In the present study, reduced scores of commitment identity style could be due to the unconstructive use of internet content. Furthermore, adolescents were found to spend more time in public spaces, such as parks and streets, compared to other places, which indicates that leisure activities in uncontrollable spaces should be decreased via effective methods.

Direct parental supervision over leisure activities of adolescents, as well as accompanying them in recreational activities (e.g., excursion in the country), could be effectual as to create a stronger 
bond between family members and enhancing mental health of teenagers.

With respect to the relationship between personal identity and gender, results of the present study indicated that diffuse identity style is more predominant among men, while commitment style is more evident among women. Findings of Aghajani et al. are consistent with our results in this regard (7). Accordingly, they claimed that with the exception of diffuse style, rate of all subscales of personal identity were higher among women (33). By contrast, results of another study reported that female participants achieved higher scores in diffusion identity style (34).

According to some scholars, biological and social factors may be involved in the formation of personal identity and social behaviors in both male and female teenagers. For instance, Bayrami believes that since gender is perceived, interpreted and valued variably in different cultures, it is essential to adopt multilateral and interdisciplinary approaches as to study the role of gender and complexities in biological, psychological, social and cultural dimensions to be able to generalize findings about personal identity (33).

In the current study, no significant difference was observed between identity styles and age of students. By contrast, results of another study in this regard showed that rates of normative and informational styles were variable among girls at different ages, while the difference in diffuse-avoidant style was not significant (35). In addition, it was stated that informational, normative and diffuse-avoidant identity styles tended to recede within late adolescence, whereas normative and informational styles reached higher levels during late adolescence compared to diffuse-avoidant identity.

In the current study, index of different products in leisure time had the highest mean score in all age groups of students. Therefore, considering the enthusiasm of new-generation teenagers towards technologies such as computer games, mobile phones and the internet, it is essential to monitor leisure activities of these young adults properly, and parents must be trained in these realms in order to have better supervision over their children.

\section{Conclusion}

According to the results of this study, leisure activities have a remarkable effect on the formation of identity style in adolescents. Considering the importance of adequate free time activities during adolescence, it is essential for families and related organizations to monitor teenagers in different areas and have proper planning for improving their quality of life through promoting beneficial spare time habits. Furthermore, community health nurses, school health experts and family physicians could be effectually involved in the management of adolescent leisure activities by offering productive consultation about methods of formal and informal training, as well as designing and implementing strategies to encourage adolescents for enjoyable educational programs.

\section{Conflict of interest}

None declared.

\section{Authors' contributions}

All authors contributed to the development, designing, data collection and analysis, drafting of the manuscript, and approving the final manuscript.

\section{Acknowledgments}

This article was extracted from a research project conducted in 2013 (code: 672) approved by the Research Deputy of Birjand University of Medical Sciences. Hereby, we extend our gratitude to the Deputy of Research for the financial support of this study. We would also like to thank the management and students of high schools in Birjand for assisting us in this research project.

\section{References}

1. Sawyer SM, Afifi RA, Bearinger LH, Blakemore SJ, Dick B, Ezeh AC, et al. Adolescence: a foundation for future health. Lancet 2012; 379(9826):1630-40.

2. Najafi M, Ahadi H, Delavar A. The relationship between 
family function and religiosity with identity crisis. Daneshvar Raftar 2006; 13(16):17-26 (Persian).

3. Neira C. Leisure time experiences in structured extracurricular activities and social networking sites predict adolescent self-concept. [Phd Dissertation]. Perth, Western Australia: School of Psychology and Exercise Science, Murdoch University; 2014.

4. Abdizarrin S, Sajjadian P, Shahiad S, Baianmemar A, Azimi H. Relationship between identity style, identity commitment and psychological well-being in guidance girl students in Qom city. Tolooe-E-Behdasht 2010; 9(1):69-77 (Persian).

5. Oswald A. Youth living in residential care: implications for leisure and identity. [Master Dissertation]. Ontario: School of Arts in Applied Health Sciences, Brock University; 2013.

6. Farzanekhou M, Yarmohammadian A, Moulavi H. Effect of general family function on identity status of students. J Behav Sci 2009; 3(2):135-42 (Persian).

7. Aghajani Hosseinabadi MH, Farzad Vali E, Shahrarai M. The comparison of identity style among undergraduate in Tehran state universities based on gender, educational course, resident and non residend. Knowl Res Appl Psychol 2010; 10(38):135-64 (Persian).

8. Shakoori A, Rafatjah M. Internet and Social Identity. Global Media J 2008; 3(1):1-17 (Persian).

9. Campbell J. Adolescent identity development: the relationship with leisure lifestyle and motivation. [Master Dissertation]. Waterloo, Ontario, Canada: Waterloo University; 2007.

10. Iman MT, Boostani D. A qualitative investigation of the intersection of leisure and identity among high school students: application of grounded theory. Qual Quant 2012; 46(2):483-99.

11. Rafatjah M. leisure and cultural norms. Iran J Cult Res 2011; 4(1):151-90 (Persian).

12. Khaje Noory B, Hasheminia F. Investigating the relationship between leisure activities and juvenile delinquency: the case of high school students in Shiraz. J Soc Sci 2010; 7(1):31-57 (Persian).

13. Jouybari L, Sanagoo A, Kavoosi A, Hesabi M, Sabzi Z. Leisure time of university students in Golestan province. J Res Dev Nurs Midwifery 2010; 7(3):65-75 (Persian).

14. Basavanthappa BT. Fundamentals of nursing. New Delhi: Jaypee Brothers Publishers; 2003. P. 68.

15. Haggard LM, Williams DR. Identity affirmation through leisure activities: leisure symbols or the self. J Leis Res
1992; 24(1):1-18.

16. Kelly JR. Leisure identities and interactions. London: George Allen and Unwin; 1983.

17. Rabbani KR, Shiri H. Leisure time and social identity: youth leisure time in Tehran. Iran J Cult Res 2010; 2(4):209-42 (Persian).

18. Ghasemi SR, Gilan NR, Reshadat S, Tavangar F, Saedi S, Soofi M. Quality of leisure time in women resident in marginal neighborhoods and its relation with health related quality of life. J Mazandaran Univ Med Sci 2015; 24(120):14-24 (Persian).

19. Ghazanfari A. Reliability and validity of identity style inventory (ISI-6G). 2004. J Psychol Educ Stud Educ Psychol 2005; 4:224-7.

20. Hejazi E, Shahraray M, Farsinejad M, Asgary A. Identity styles and academic achievement: mediating role of academic self-efficacy. Soc Psychol Educ 2009; 12(1):12335.

21. Agnew R, Peterson David M. Leisure and delinquency. Soc Prob 1989; 36(4):332-50.

22. Yin Z, Katims DS, Zapata JT. Participation in leisure activities and involvement in delinquency by Mexican American adolescents. Hispanic J Behav Sci 1999; 21(2):170-85

23. Khanifar H, Bordbar H, Foroghi Ghomi F. Relation between student's identity style and happiness and how to develop happiness among students (case study: Ghom campus students of Tehran university). Cult Islamic Univ 2012; 2(1):24-50 (Persian).

24. Rahmani A, Pour-ranjbar M, Bakhshinia T. Evaluation and comparison of Zanjan universities female students leisure activities: the role of sport and physical education. J Rafsanjan Univ Med Sci 2006; 5(3):209-16 (Persian).

25. Mozafary A, Safania A. The way of spending leisure time of Islamic Azad university students insisting in sport activities. Olympic 2004; 12(1):117-26 (Persian).

26. Larson RW, Hansen DM, Moneta G. Differing profiles of developmental experiences across types of organized youth activities. Dev Psychol 2006; 42(5):849-63.

27. Munson WW, Widmer MA. Leisure behavior and occupational identity in university students. Car Dev Q 1997; 46(2):190-8.

28. Shaw SM, Kleiber DA, Caldwell LL. Leisure and identity formation in male and female adolescents: a preliminary examination. J Leisure Res 1995; 27(3):245-63.

29. Ebrahimi GA, Behnoei Gadaneh A. Leisure and identity: a sociological study of the relationship between leisure and 
personal identity among young of Babolsar. Cult Commun Stud J 2009; 5(14):196 (Persian).

30. Maleki A, Abaspour A. Social evaluation of young individuals' viewpoint on national identity and its factors. Q Police Sci 2010; 10:159-76 (Persian).

31. Alavi SS, Hashemian K, Janati Fard F. Identity status and mental health in internet-user students in Tehran University. Behav Sci Stud 2008; 6(1):27-35 (Persian).

32. Hafeznia MR, Kaviani Rad M, Taherkhani M. Globalization and national identity (Case study: students of state universities in Tehran). Geopolitics 2007; 2(3):1-21 (Persian).

33. Mousavi R, Akbari Zardkhaneh S, Ramazani V. Sexual differences in identity aspects of students. Counsel Cult 2012; 2(8):31-46 (Persian).

34. Bayrami M. Comparison of identity styles and types of identity in male and female. J Psychol (Tabriz Univ) 2011; 5(20):21-39 (Persian).

35. Tanhaye Reshvanloo F, Keramati R, Seadatee Shamir A. Optimism and self-esteem in teenager girls: the role of identity styles. J Appl Psychol 2012; 6(2):73-90 (Persian). 